\title{
Experimental evidence for the ancestry of allotetraploid Trifolium repens and creation of synthetic forms with value for plant breeding
}

\author{
Warren M Williams ${ }^{1,2^{*}}$, Nicholas W Ellison ${ }^{1}$, Helal A Ansari ${ }^{1}$, Isabelle M Verry ${ }^{1}$ and S Wajid Hussain ${ }^{1}$
}

\begin{abstract}
Background: White clover (Trifolium repens) is a ubiquitous weed of the temperate world that through use of improved cultivars has also become the most important legume of grazed pastures world-wide. It has long been suspected to be allotetraploid, but the diploid ancestral species have remained elusive. Putative diploid ancestors were indicated by DNA sequence phylogeny to be T. pallescens and T. occidentale. Here, we use further DNA evidence as well as a combination of molecular cytogenetics (FISH and GISH) and experimental hybridization to test the hypothesis that white clover originated as a hybrid between T. pallescens and T. occidentale.

Results: T. pallescens plants were identified with chloroplast trnL intron DNA sequences identical to those of white clover. Similarly, T. occidentale plants with nuclear ITS sequences identical to white clover were also identified. Reciprocal GISH experiments, alternately using labeled genomic DNA probes from each of the putative ancestral species on the same white clover cells, showed that half of the chromosomes hybridized with each probe. $F_{1}$ hybrids were generated by embryo rescue and these showed strong interspecific chromosome pairing and produced a significant frequency of unreduced gametes, indicating the likely mode of polyploidization. The $F_{1}$ hybrids are inter-fertile with white clover and function as synthetic white clovers, a valuable new resource for the re-incorporation of ancestral genomes into modern white clover for future plant breeding.

Conclusions: Evidence from DNA sequence analyses, molecular cytogenetics, interspecific hybridization and breeding experiments supports the hypothesis that a diploid alpine species (T. pallescens) hybridized with a diploid coastal species (T. occidentale) to generate tetraploid $T$. repens. The coming together of these two narrowly adapted species (one alpine and the other maritime), along with allotetraploidy, has led to a transgressive hybrid with a broad adaptive range.
\end{abstract}

Keywords: Trifolium repens, White clover, Allopolyploid, Interspecific hybridization

\section{Background}

White clover, an allotetraploid $(2 \mathrm{n}=4 \mathrm{x}=32)$ stoloniferous herb, is naturally distributed through the grasslands of Europe, W Asia and N Africa, from low to high latitudes and altitudes and, because of its broad adaptation, has become the most extensively used legume of grazed pasture world-wide. Its origin has been long debated [1-4]. The identity of the ancestors has remained elusive and, despite many attempts [e.g. 3,5-7] there has been

\footnotetext{
*Correspondence: warren.williams@agresearch.co.nz

${ }^{1}$ AgResearch Grasslands Research Centre, Private Bag 11008, Palmerston North, 4442, New Zealand

${ }^{2}$ College of Sciences, Massey University, Palmerston North, 4442, New Zealand
}

\section{Biomed Central}

no successful re-synthesis. A phylogenetic analysis of Trifolium based on the nuclear internal transcribed spacer region of 18 S-26 S rDNA (ITS) and chloroplast trnL intron DNA (cpDNA) sequences [8] suggested that the closest extant diploid ancestors were $T$. pallescens $(2 \mathrm{n}=2 \mathrm{x}=16)$ and T. occidentale $(2 \mathrm{n}=2 \mathrm{x}=16)$.

T. occidentale is a predominantly self-fertile, strictly maritime species with a very narrow adaptation, occurring only very close to the sea in confined habitats on the gulfstream coasts of Europe [9] (Figure 1a). T. pallescens is a predominantly cross-pollinating but self-fertile alpine clover, presently occurring only above 1,800 meters in Europe (Figure $1 \mathrm{~b})$. It has a narrow adaptation within the alpine zone [10]. 


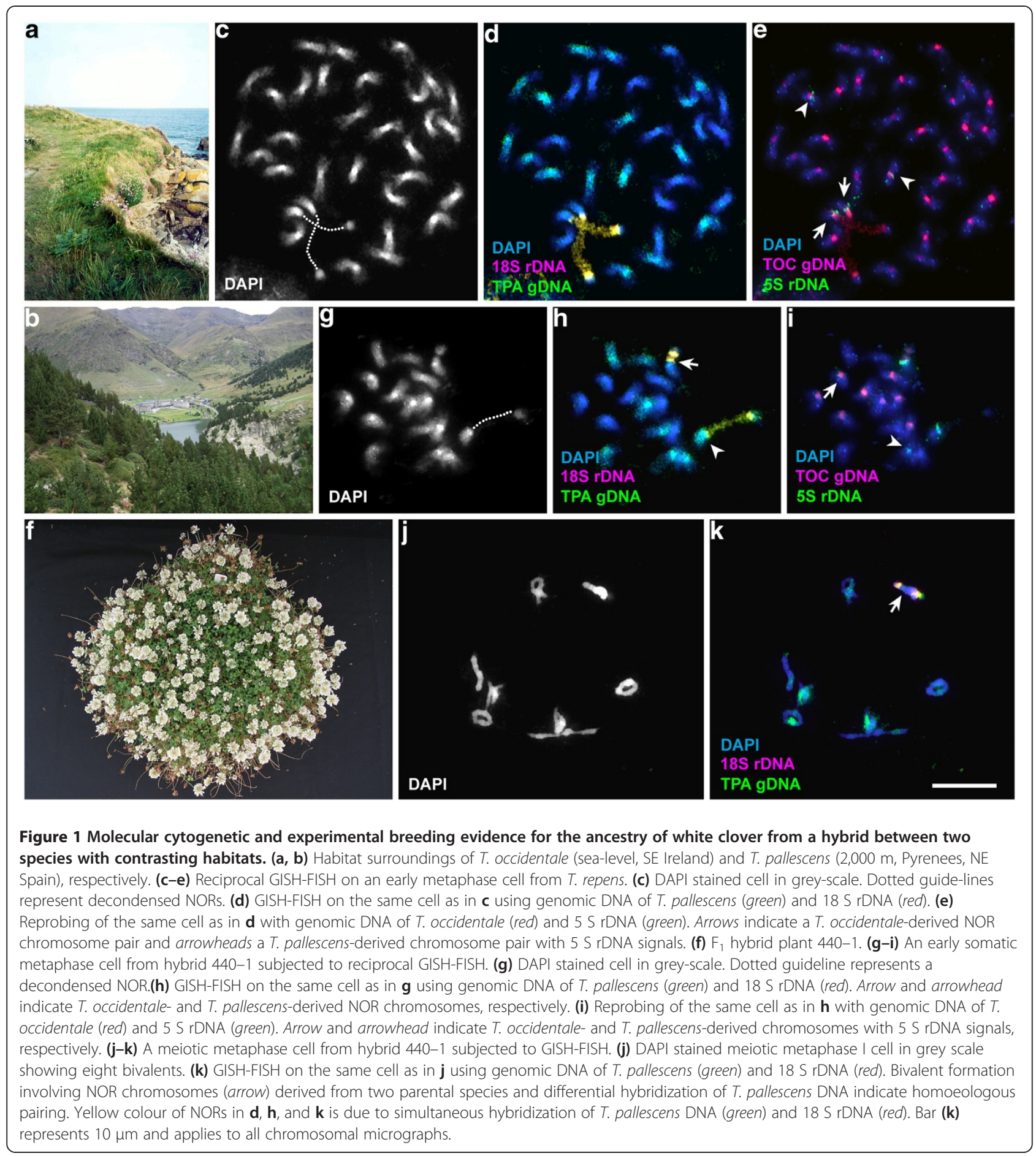

Nearly identical ITS sequences [8], SNP analyses [11] and synteny of SSR markers [12] strongly supported $T$. occidentale as the source of one sub-genome. Chloroplast DNA sequences of $T$. pallescens were similar to white clover, while all 200 other species investigated were markedly more divergent [8]. To-date, based on cpDNA, T. pallescens is the closest extant species to the maternal ancestor of white clover. Nevertheless, genic SNP comparisons of $T$. pallescens and white clover sub-genomes showed weaker than expected matching, and it was suggested that a taxon closely related to $T$. pallescens, but as yet unidentified, may have been the ancestor [11].

We undertook experimental tests of the hypothesis that white clover arose following hybridization between $T$. pallescens and T. occidentale, and here present evidence from DNA sequence analyses, molecular cytogenetics, 
interspecific hybridization and post-hybridization experiments. The results support the hypothesis and suggest a proposed sequence of events that led to the origin of this widely adapted polyploid species from two very narrowly adapted diploid ancestors via unreduced gametes in an otherwise sterile interspecific $\mathrm{F}_{1}$ hybrid. The ability to produce synthetic forms has opened the way to expand the gene-pool of white clover to include current populations of the ancestral species.

\section{Results}

\section{DNA sequences}

In the present work, comparisons were made of the cpDNA sequences of white clover and five geographically divergent T. pallescens accessions, all verified by their distinctive ITS DNA sequence. Two $T$. pallescens specimens from $\mathrm{N}$ Greece had identical cpDNA sequences (GenBank JN881726, JN881727) to the 580 bp $T$. repens reference sequence (GenBank DQ311961). An Austrian (Tyrol) population AZ4856 and AZ1895 (source uncertain) differed from $T$. repens only at positions $143-148$, where AAAAAA in $T$. repens was reduced to AA in T. pallescens [8]. A Spanish Pyrenees population (AZ4837, GenBank JN982466) was identical to $T$. repens at that site but differed by a five bp ATATA insertion at positions 289-290. Analysis of ITS sequences from several T. occidentale populations supported the hypothesis that T. occidentale was the other ancestral parent. Some T. occidentale populations had identical 738 bp ITS sequences to white clover, while others differed from white clover at one of two SNP positions.

\section{Genomic in situ hybridization}

Genomic in situ hybridization (GISH) using labeled $T$. pallescens genomic DNA showed that half of the chromosomes of white clover hybridized strongly (Figure 1c, d), supporting the hypothesis that T. pallescens, or a very close relative, was an ancestor. The arms of the single pair of $T$. repens NOR-carrying chromosomes did not show hybridization, indicating that this chromosome pair was contributed by the other ancestral parent. A reciprocal GISH experiment, using labeled genomic DNA of $T$. occidentale on the same preparations (Figure. 1e), led to the stronger hybridization of centromeric regions and faint arms of the other 16 chromosomes, including the two NOR-carrying chromosomes, and supporting T. occidentale as the donor of the NOR-bearing genome. Stronger GISH hybridization in the centromeric regions can be caused by the clustering of repetitive sequences in this region [13]. Major clustering of a repetitive sequence, TrR350, at centromeres of $T$. repens and $T$. occidentale has been reported previously [14]. It may also be noted that a pair of chromosomes marked only with a minor $5 \mathrm{~S}$ rDNA sequence (Figure 1e) is strongly hybridized with $T$. pallescens genomic DNA (Figure 1d).

\section{Hybridization of $T$. pallescens and T. occidentale}

No mature seeds were recovered from reciprocal interspecific crosses and no hybrid embryos were formed when $T$. occidentale was used as the female parent. Pollination of $T$. pallescens with $T$. occidentale yielded frequent $0.5 \mathrm{~mm}$-long torpedo-stage embryos that were rescued nine days postpollination and cultured on the artificial media where they developed into plantlets. Approximately 200 plantlets from 18 crosses were transplanted to potting mix in the greenhouse, where most languished, failed to develop beyond 35 leaves and did not flower. Only four developed into large plants that grew strongly and flowered prolifically (Figure 1f). All four hybrids were derived from AZ1895 T. pallescens as female and two of the four had the same parents (Table 1).

Small leaflets densely covered the hybrid plants. Like the male parent, the plants were stoloniferous with rooting at the vegetative nodes. Inflorescences occurred in the leaf axils and petals were pink, like those of the maternal parent.

\section{Cytogenetic analysis and fertility of the hybrids}

Two hybrid plants $(440-1,1854)$ were diploid $(2 \mathrm{n}=16$, Table 2, Figure 1g). Two others with tiny, indehiscent anthers and $<1 \%$ stainable pollen were not studied further. Reciprocal GISH on somatic chromosomes of hybrid 440-1 confirmed that half the chromosomes were derived from $T$. pallescens (Figure 1g, h) and the remaining half from $T$. occidentale (Figure 1i). There was evidence of nucleolar dominance and GISH showed that the T. pallescens-derived NOR was decondensed and the $T$. occidentale NOR was condensed (Figure 1g-i).

Meiotic analyses of hybrid 440-1 on a sample of $>300$ pollen mother cells (PMCs) showed all had eight bivalents (Table 2, Figure 1j) and 8-8 disjunction at anaphase I. GISH on PMCs of the hybrid (Figure 1k) confirmed homoeologous chromosome pairing as evidenced by a bivalent with $18 \mathrm{~S}$ rDNA signals from both species and by the differential painting of other bivalents. Despite this apparent regularity, scanning of large numbers of PMCs revealed occasional multivalent formation and some unequal chromosome distribution in tetrads.

Both male and female fertility were low. As a guide to pollen fertility, the frequency of mature pollen stained was $5 \%$ in hybrid $440-1$ (Table 2 ) and $1.5-2.0 \%$ in hybrid

Table 1 Parents and leaf marks of $F_{1} T$. pallescens $x$ $T$. occidentale hybrids that reached maturity

\begin{tabular}{llll}
\hline F $_{\mathbf{1}}$ plant & T. pallescens female & T. occidentale male & Leaf mark \\
\hline 440-1 & AZ 1895-3 self-2 & OCD 1166-4 & Unmarked \\
\hline 1854 & AZ 1895-18 & OCD 1168-14 & Unmarked \\
\hline Hybrid 3 & AZ 1895-3 self-2 self-49 & OCD 1162-17 & Unmarked \\
\hline Hybrid 4 & AZ 1895-3 self-2 self-49 & OCD 1162-17 & V mark \\
\hline
\end{tabular}


Table 2 Somatic chromosome number, meiotic configurations and pollen stainability in $F_{1}, F_{2}$ and OP plants

\begin{tabular}{|c|c|c|c|c|c|c|c|c|}
\hline \multirow[t]{3}{*}{ Genotype } & \multirow{3}{*}{$\begin{array}{l}\text { Somatic chromosome } \\
\text { number }\end{array}$} & \multirow{3}{*}{$\begin{array}{l}\text { Number } \\
\text { of PMC }\end{array}$} & \multicolumn{4}{|c|}{ Meiotic configurations } & \multirow{3}{*}{$\begin{array}{l}\text { Anaphase I } \\
\text { disjunction }\end{array}$} & \multirow{3}{*}{$\begin{array}{l}\text { Pollen } \\
\text { stainability }\end{array}$} \\
\hline & & & 1 & II & III & IV & & \\
\hline & & & $\overline{\bar{x}}$ (range) & $\overline{\mathrm{x}}$ (range) & $\bar{x}$ (range) & $\bar{x}$ (range) & & \\
\hline $440-1$ & $2 n=2 x=16$ & $>300$ & $0(0)$ & $8(0)$ & $0(0)$ & $0(0)$ & $8-8$ & $5 \%$ \\
\hline $880-1$ & $2 n=4 x=32$ & 80 & $0(0)$ & $8(6-10)$ & $0(0)$ & $4(3-5)$ & $16-16$ & $78 \%$ \\
\hline 440-1 OP-3 & $2 n=4 x=32$ & 70 & $0(0)$ & $8(6-14)$ & $0(0)$ & $4(1-6)$ & $16-16$ & $18 \%$ \\
\hline 440-1 OP-9 & $2 n=4 x=32$ & 55 & $0(0)$ & $9(8-14)$ & $0(0)$ & $3.5(1-4)$ & $16-16$ & $27 \%$ \\
\hline $440-1$ OP- 55 & $2 n=4 x=32$ & 63 & $0(0)$ & $8.2(6-12)$ & $0(0)$ & $3.9(2-5)$ & $16-16$ & $53 \%$ \\
\hline $440-1$ OP-88 & $2 n=4 x+1=33$ & 13 & $2.2(1-5)$ & $8.1(2-14)$ & $0.85(0-2)$ & $3.0(0-5)$ & $16-17$ & $43 \%$ \\
\hline $440-1$ OP-153 & $2 n=3 x=24$ & 43 & $2.0(1-4)$ & $2.6(1-5)$ & $5.6(4-7)$ & $0(0)$ & $12-12^{*}$ & $11 \%$ \\
\hline$\overline{F_{2}(2 x)^{\dagger}}$ & $2 n=2 x=16$ & 475 & $0(0)$ & $8(0)$ & $0(0)$ & $0(0)$ & $8-8$ & \\
\hline
\end{tabular}

* two cells showed 11-13 disjunction and approximately 10 showed lagging chromosomes at anaphase $\mathrm{I}$.

${ }^{\dagger}$ seven verified $2 x$ plants produced from open pollination of 440-1. Two cells from one plant had 7 II and 2 I.

1854. On the assumption of self-fertility (as for the female parent), more than 100 heads of hybrid 440-1 were selfpollinated but no pods or seeds developed. Subsequently, 20 cloned ramets of hybrid 440-1 (lacking leaf markings), were placed in an outdoor nursery alongside plants of $T$. repens (with co-dominant leaf markings) and the diploid parent species. Prolific flowering of 440-1 occurred over an extended period and hundreds of inflorescences were harvested. Open-pollinated (OP) seed-set was very low (less than one per 100 florets) but more than 200 OP seeds were obtained. Similarly, six ramets of hybrid 1854 were open-pollinated and about 35 seeds were obtained.

\section{Analysis of open-pollinated progeny}

From hybrid 440-1, 184 seeds were imbibed and these produced 79 well-established, putative hybrid progeny plants. Of the remainder, 53 failed to germinate and 52 died as seedlings. Forty-four well-established plants were verified by DNA sequence analysis to be carrying $T$. pallescens chloroplasts from the maternal 440-1 plant. The others were either not tested (25) or were contaminants (10). More than half (26) of the verified plants resembled white clover in phenotype and/or carried leaf marks that indicated that the pollen parent was white clover (Table 3).
Nineteen of these were tested and 18 were confirmed as tetraploid, i.e. derived by union of an unreduced (2n) egg from $440-1$ with normal $2 x$ pollen from $T$. repens. Such plants would be expected to have three satellite (NORbearing) chromosomes - two from the 440-1 hybrid $2 n$ egg and one from a normal $2 \times 1$. repens male gamete. This was checked for five plants and confirmed in all cases. One of the tetraploid plants with three NOR-chromosomes carried an additional chromosome $(2 \mathrm{n}=4 \mathrm{x}+1=33)$. The last of the 19 plants, resembling a slender form of white clover, was verified as triploid $(2 n=3 x=24)$. The presence of leaf markings and only two satellite chromosomes indicated that this triploid had arisen from a fusion between a haploid female gamete from $440-1$ and a normal $2 \mathrm{x}$ white clover male gamete. The other 18 verified plants from $440-1$ resembled diploid T. pallescens or T. occidentale. Chromosome counts or flow cytometry have confirmed all 12 tested plants to be diploid (Table 3). Open pollination of the second $F_{1}$ (1854) produced 30 progeny plants (verified as above), three of which survived to flowering. Two were confirmed as tetraploid and the third died before it could be tested.

The majority of the (T. pallescens $\times T$. occidentale) $\mathrm{x} T$. repens tetraploids were morphologically identical to

Table 3 Characteristics of 440-1 OP progeny with maternity confirmed by presence of $T$. pallescens trnL intron

\begin{tabular}{|c|c|c|c|c|c|c|c|c|c|}
\hline \multirow[t]{2}{*}{ Appearance } & \multirow[t]{2}{*}{ Ploidy } & \multirow{2}{*}{$\begin{array}{l}\text { No } \\
\text { plants }\end{array}$} & \multirow{2}{*}{$\begin{array}{l}\text { With leaf } \\
\text { mark* }^{*}\end{array}$} & \multirow{2}{*}{$\begin{array}{l}\text { No leaf } \\
\text { mark }\end{array}$} & \multicolumn{5}{|c|}{ Pollen stainability (\%) } \\
\hline & & & & & ND & $0-9$ & $10-39$ & $40-59$ & $60+$ \\
\hline \multirow[t]{3}{*}{ White clover-like } & $4 x^{\dagger}$ & 19 & 16 & 3 & 4 & 1 & 5 & 8 & 1 \\
\hline & $3 x$ & 1 & 1 & - & - & - & 1 & - & - \\
\hline & ND & 6 & 6 & - & 1 & 1 & 3 & 1 & 0 \\
\hline \multirow[t]{2}{*}{ Diploid-like } & $2 x$ & 12 & 2 & 10 & 6 & 2 & 3 & 1 & 0 \\
\hline & ND & 6 & 1 & 5 & 3 & 2 & 1 & 0 & 0 \\
\hline
\end{tabular}

* 4x plants carried leaf marks conditioned by $\mathrm{V}$ and $\mathrm{R}$ alleles from white clover [15]. Leaf-marked 2x plants resembled, and carried an $\mathrm{R}$ allele from, $T$. occidentale.

+ One $4 x$ plant carried an additional chromosome.

ND (not determined). 
white clover but showed lower male and female fertility and higher self-compatibility. A few plants showed developmental abnormalities such as small, wrinkled leaves and/or weak chlorophyll development in young leaves. Pollen stainabilities ranged from $0-72 \%$ (Table 3, control T. repens $98-100 \%)$. Eleven verified tetraploid plants were self-pollinated and all except two produced seeds (4-33 per inflorescence compared with 0.6 per inflorescence for a white clover control), indicating self-compatibility (Table 4). The same plants were backcrossed as females to $T$. repens and all except the two apparently female-sterile plants produced 2-41 seeds per inflorescence, a marked reduction compared with over 100 seeds for control white clover (Table 5).

Four tetraploid plants and one triploid were analyzed for meiotic chromosome pairing (Table 2). All tetraploids averaged 3-4 quadrivalent associations per cell. One (440-1 OP-88) had an additional chromosome, and showed 1-5 univalents and $0-2$ trivalents per cell at metaphase I. The triploid plant (440-1 OP-153) showed a predominance of trivalent chromosome associations and low numbers of univalents and bivalents (Table 2). The selfed seed from two tetraploid OP plants was grown. In one case (440-1 OP-3 selfed), 19 seeds gave 17 plants, of which 12 were robust and white clover-like, three were slightly less robust and two were small with abnormal leaf morphology and/or pale green leaf sectors. The second plant (440-1 OP-4) was abnormal and, when six selfed seeds were grown, gave two strong, one medium and three very weak plants. When two 440-1 OP-3 selfed progeny plants were further selfed and backcrossed to white clover, the seed-sets were low, indicating reduced fertility (Tables 4 and 5).

Table 4 Results of selfing tetraploid 440-1 OP progeny plants

\begin{tabular}{llll}
\hline Plant selfed & No heads & No seeds & Seeds/head \\
\hline $440-1$ OP-3 & 2 & 19 & 9 \\
\hline $440-1$ OP-8 & 5 & 89 & 18 \\
\hline $440-1$ OP-9 & 5 & 88 & 18 \\
\hline $440-1$ OP-21 & 5 & 95 & 19 \\
\hline $440-1$ OP-57 & 4 & 35 & 9 \\
\hline $440-1$ OP-70 & 2 & 26 & 13 \\
\hline $440-1$ OP-72 & 3 & 100 & 33 \\
\hline $440-1$ OP-76 & 2 & 8 & 4 \\
\hline $440-1$ OP-88* & 5 & 102 & 20 \\
\hline $440-1$ OP-90 & 4 & 0 & 0 \\
\hline $440-1$ OP-110 & 4 & 0 & 0 \\
\hline T. repens & 5 & 3 & 0.6 \\
\hline $440-1$ OP-3 self-5 & 4 & 27 & 6 \\
\hline $440-1$ OP-3 self-12 & 5 & $3+7$ small & 2 small \\
\hline$* 2 n=33$ (carrying an additional chromosome). &
\end{tabular}

Table 5 Seed-set from backcrossing verified tetraploid progeny plants of 440-1 to white clover (WC)

\begin{tabular}{|c|c|c|c|c|}
\hline Female & WC male & No. heads & No. seeds & Seeds/head \\
\hline 440-1 OP-3 & $(\mathrm{PxB})-17$ & 4 & 64 & 16 \\
\hline 440-1 OP-8 & C21557-1 & 1 & 22 & 22 \\
\hline 440-1 OP-8 & Will-2 & 3 & 53 & 18 \\
\hline 440-1 OP-9 & $(\mathrm{P} \times \mathrm{B})-5$ & 1 damaged & 2 & 2 \\
\hline 440-1 OP-21 & $(\mathrm{P} \times \mathrm{B})-5$ & 3 & 39 & 13 \\
\hline 440-1 OP-57 & $(\mathrm{P} \times \mathrm{B})-5$ & 3 & 32 & 11 \\
\hline 440-1 OP-70 & C21557-1 & 2 & 5 & 3 \\
\hline 440-1 OP-72 & C21557-1 & 3 & 68 & 23 \\
\hline 440-1 OP-76 & C21557-1 & 2 & 7 & 4 \\
\hline 440-1 OP-88 & $(P \times B)-5$ & 3 & 122 & 41 \\
\hline 440-1 OP-90 & C21557-1 & 2 & 2 & 1 \\
\hline $440-1$ OP-110 & C21557-1 & 3 & 0 & 0 \\
\hline WC control & $(\mathrm{P} \times \mathrm{B})-5$ & 1 & 105 & 105 \\
\hline 440-1 OP-3 self-5 & $(\mathrm{P} \times \mathrm{B})-5$ & 3 & $10+3$ small & $3-4$ \\
\hline 440-1 OP-3 self-12 & $(\mathrm{P} \times \mathrm{B})-5$ & 3 & $14+7$ small & $4-7$ \\
\hline
\end{tabular}

\section{An artificial allotetraploid (synthetic white clover)}

The chromosomes of hybrid 440-1 were colchicinedoubled to produce an amphidiploid (880-1). This plant showed an improved pollen stainability of $78 \%$, was selfcompatible and freely set seeds in reciprocal crosses with white clover (Table 6). Self-pollination of 880-1 produced about 4 seeds/head and led to about $50 \%$ fully developed seeds and 50\% shrunken seeds and unfilled testas. Fourteen selfed-seeds were set for germination, 11 germinated, and 9 grew to mature plants. Cross-pollination of $880-1$ with white clover plants gave some seed-sets per head of

Table 6 Seed-set following self-pollination and reciprocal crosses with white clover for hybrid 880-1 and a selfed derivative

\begin{tabular}{|c|c|c|c|}
\hline Female $x$ Male & Heads & Seeds & Seeds/head \\
\hline \multicolumn{4}{|l|}{$4 x$ hybrid self pollinations } \\
\hline $880-1$ self & 8 & 32 & 4 \\
\hline $880-1$ self-5 self & 8 & 155 & 19 \\
\hline \multicolumn{4}{|l|}{$4 \times$ hybrid $x$ white clover } \\
\hline 880-1 x Crusader-29 & 9 & 40 & 4 \\
\hline 880-1 x Kopcru-1 & 5 & 41 & 8 \\
\hline \multicolumn{4}{|l|}{ White clover $x 4 \times$ hybrid } \\
\hline Kopu II-2 x 880-1 & 2 & 88 & 44 \\
\hline Kopcru-1 x 880-1 & 12 & 384 & 32 \\
\hline C 6452-4 x 880-1 & 2 & 90 & 45 \\
\hline C 11519-4 x 880-1 & 3 & 55 & 18 \\
\hline Kopu II-2 x 880-1 self-5 & 2 & 164 & 82 \\
\hline Kopcru-1 x 880-1 self-5 & 4 & 130 & 32 \\
\hline \multicolumn{4}{|l|}{ White clover control } \\
\hline Kopu II-2 x Crusader-29 & 1 & 120 & 120 \\
\hline
\end{tabular}


over 40 (Table 6). Thus, the raw synthetic hybrid was reasonably freely inter-fertile with white clover. Analysis of the progeny plants from these crosses showed reduced survival, pollen stainability and seed-set relative to white clover controls (Table 7), although some synthetic derivatives had pollen fertility approaching white clover plants. One of the self-progeny plants (880-1 self-5), was self-fertile and averaged 32 and 82 seeds per head when crossed as male with two white clover plants, including one individual with 127 seeds - the same as the white clover control (Table 6) indicating that a selfed derivative of the synthetic allotetraploid was highly inter-fertile with white clover.

\section{Attempts to obtain a spontaneous allotetraploid}

The confirmation of tetraploid progeny following openpollination of 440-1 indicated the functioning of $2 \mathrm{n}$ female gametes in this diploid hybrid. On the assumption that $2 \mathrm{n}$ male gametes might also be functional, several attempts were made to form an allotetraploid by self pollination. However, this was unsuccessful despite more than 1,000 hand pollinations with large amounts of pollen, and bee pollinations of hundreds of inflorescences in an insect cage. Hand pollinations of 440-1 with known diploid pollen sources (880-1 and T. repens) also failed to produce seeds, suggesting that the frequency of female unreduced gametes was too low to enable detection from these controlled crosses.

\section{Discussion}

The present evidence validates the hypothesis that white clover, $T$. repens, arose following the hybridization of progenitor taxa very similar to modern $T$. pallescens and T. occidentale to form a partially fertile diploid hybrid(s). In the present experimental open pollination situation, unreduced (2n) gametes from the hybrids readily combined with natural $(2 x)$ gametes from white clover to produce hybrids that closely resembled white clover. We hypothesize that the original $F_{1}$ hybrid(s) produced unreduced gametes, leading to a transgressive allotetraploid form. Such allotetraploids frequently exhibit markedly

Table 7 Viability of progeny from crosses between white clover plants and hybrid 880-1

\begin{tabular}{llllll}
\hline Female x Male & $\begin{array}{l}\text { No } \\
\text { seeds }\end{array}$ & $\begin{array}{l}\text { No } \\
\text { plants }\end{array}$ & $\begin{array}{l}\text { No plants } \\
\text { flowering }\end{array}$ & $\begin{array}{l}\text { PS\% } \\
\text { (range) }\end{array}$ & $\begin{array}{l}\text { Seeds/head } \\
\text { (range) }\end{array}$ \\
\hline $880-1 \times$ Crusader-29 & 12 & 12 & 12 & $3-85$ & $4-50$ \\
\hline $880-1 \times$ Kopcru-1 & 10 & 10 & 10 & $0-73$ & $0-19$ \\
\hline Kopu II-2 x 880-1 & 11 & 6 & 5 & $22-62$ & $9-29$ \\
\hline Kopcru-1 x 880-1 & 12 & 12 & 12 & $21-63$ & $1-21$ \\
\hline C6452-4 x 880-1 & 12 & 11 & 11 & $24-61$ & $0-29$ \\
\hline C11519-4 x 880-1 & 12 & 10 & 7 & $34-78$ & $1-34$ \\
\hline Kopu II-2 x Crusader-29 & 12 & 12 & 12 & $98-100$ & $230-420$ \\
\hline
\end{tabular}

Seeds/head data were based on means of a minimum of three open-pollinated heads per plant at a single harvest. PS $\%=\%$ stained pollen. better fertility and broader adaptive capacity through polyploidy, heterozygosity and genomic plasticity [16]. Thus, $T$. repens, a widely adapted aggressive weedy species (with agronomic value as well) arose from two species, the modern forms of which are now comparatively rare and narrowly adapted. The primary allotetraploid probably had two pairs of NOR-carrying chromosomes. Post-hybridization genomic changes have reduced the NORs to one pair in modern white clover populations.

Analyses presented here provide evidence that $T$. pallescens and $T$. occidentale are the closest known modern relatives of the ancestral parents of white clover. It was shown that the chloroplast trnL intron DNA sequences of two populations of T. pallescens were identical with white clover, and another three populations were more similar than any other known species to those of $T$. repens. In addition, reciprocal GISH experiments demonstrated that half of the chromosomes of $T$. repens hybridized strongly with genomic DNA of $T$. pallescens and the other half with T. occidentale genomic DNA. Furthermore, plants from T. pallescens (AZ1895) could be crossed with $T$. occidentale to produce diploid hybrids that were inter-fertile with white clover via unreduced gametes. Thus these modern populations were close enough to the ancestors to be able to replace them in both GISH and in the production of synthetic hybrids.

During glacial episodes in Europe, alpine species such as T. pallescens were forced into low altitude refuges $[17,18]$. Such refuges included coastal regions of W Portugal and Spain, where $T$. occidentale currently occurs, as well as regions further east (e.g. the Balkans) where T. repens var. biasolettii and var. macrorrhizum (forms similar to $T$. occidentale [19]) occur. Hybridization might, therefore, have taken place in such a refuge during a glacial period. The small divergences in DNA sequences between extant T. pallescens populations from the Pyrenees, the Austrian Alps and N Greece are consistent with their separate evolution as they subsequently regressed to different alpine regions as the climate warmed after successive glaciations. The largest DNA sequence differences in the chloroplast trnL intron between white clover and extant T. pallescens populations can be explained by single insertion/deletion changes. Similarly, the largest differences found to-date between $T$. occidentale and $T$. repens ITS sequences were single bp differences. Such singular changes cannot be dated, and so a molecular clock cannot yet be applied. Their singular nature suggests that they could be recent, possibly occurring during or since the period of complex temperature fluctuations spanning the last two major glaciations 130,000-13,000 years ago [20].

Although there has been no comprehensive study of chloroplast inheritance patterns in Trifolium, a limited study of several species, including white clover, indicated that maternal inheritance occurred without 
exception [21]. In the present study, we found that maternal inheritance of $T$. pallescens chloroplasts occurred and, furthermore, used this to verify the authenticity of the progeny obtained from the $F_{1}$ hybrids. Thus it is likely that $T$. pallescens was the maternal ancestor.

It is expected that some genomic divergence could have occurred since hybridization not only within the parent species, but also in the sub-genomes within white clover populations. The extent of such divergences would reflect the length of time as well as the effects of habitat pressures and natural selection since hybridization. In this context, the identity, and close similarity, of chloroplast DNA sequences, and the GISH and plant hybridization results are compelling evidence in favor of T. pallescens as the maternal ancestor. Any alternative female ancestor must have been so close to $T$. pallescens as to have strong affinities in the dispersed repeat DNA responsible for GISH genomic differentiation. It must also have been so close that the modern $T$. pallescens genome can substitute functionally for it in artificial hybrids. However, the need for embryo rescue to achieve the crosses suggests some difference in reproductive biology from ancestral forms. In the same way, similarities of $T$. occidentale nuclear DNA sequences with those of $T$. repens provide strong evidence that $T$. occidentale was the other (and probably the male) ancestor.

T. pallescens has evolved into divergent, widely separated sub-alpine and alpine populations in the Pyrenees and Massif Centrale and across the Alps of $\mathrm{C}$ and S Europe to Greece, Romania and Bulgaria. We have shown that populations from the Pyrenees, Austrian Alps and Greece differed in trnL intron DNA sequences. Apparently different forms of T. pallescens have developed in isolation in different alpine 'islands' in Europe, possibly as the populations retreated to alpine habitats with climate warming, as discussed above. Even populations of T. pallescens in adjacent valleys in the Tyrol show some genetic differentiation [10]. It would therefore not be surprising if populations as far apart as Spain and Greece showed considerable differentiation. The finding [11] that nuclear gene SNPs differentiated the T. pallescens (AZ1895) genome from both sub-genomes of white clover may be consistent with the finding of genomic variation among $T$. pallescens populations.

While it is significant that at least two specimens (from Greece) have been found with identical trnL intron sequences to that of white clover, it is likely that a wider sampling of $T$ pallescens genomic variation would reveal more about the distribution of the ancestral populations and the region of origin of white clover. The great geographic distance between extant $T$. occidentale and the Greek T. pallescens populations is inconsistent with the hypothesis that they formed hybrids. Further sampling might reveal $T$. pallescens populations with identical cpDNA sequences to white clover in W Europe.
Alternatively, T. occidentale might previously have had a wider distribution. Clover forms from eastern Europe, Turkey and Iran with hairy petioles and pedicels similar to T. occidentale are T. repens var. biasolettii and var. macrorrhizum [19], which could represent relict eastern forms. However, our DNA sequence analyses to-date (one specimen of each) suggest that they are forms of white clover.

White clover and its wild relatives occur as a species complex with close affinities in DNA sequences, chromosome pairing and crossability, indicating recent and rapid speciation and distribution across Europe, W Asia and $\mathrm{N}$ Africa [22]. The complex includes several other species in section Trifoliastrum [8,23]: T. nigrescens, T. ambiguum, T. uniflorum, T. isthmocarpum and T. thalii [24]. Although hybridization between $T$. pallescens and $T$. occidentale appears to have been the main factor in the origin of white clover, some introgression from other species in the complex may also have occurred. One gene that may have introgressed in this manner is $\mathrm{Li}$, conditioning the production of linamarase, an enzyme that degrades cyanogenic glucosides, and one that is very common in white clover [25]. So far $L i$ has not been found in either T. pallescens or T. occidentale, although the latter is polymorphic for production of cyanogenic glucosides [26]. The only close relative known to carry $L i$ is $T$. nigrescens $[27,28]$ which can hybridize with both $T$. repens and $T$. occidentale [7], providing possible alternative routes for introgression.

Both ancestral species are predominantly self-compatible but have given rise to a self-incompatible species with a well characterized gametophytic oppositional $S$ allele incompatibility system [15]. Therefore the origin of the white clover $S$ locus should be addressed. One possibility is that it came from the ancestral T. occidentale populations. Extant populations of $T$. occidentale from a confined region of $\mathrm{NW}$ Spain are self-incompatible [12] and so the $S$ locus could have been introduced directly or indirectly from the ancestral source. Alternatively, as T. nigrescens also has a well defined $S$ allele incompatibility system [29], it could have come by introgression from that species as suggested for $L i$.

A property of new allopolyploids, contributing to their evolutionary success, is genomic plasticity $[16,30]$. This plasticity provides the ability to withstand large, rapid genomic changes including diploidization, and leads to the development of new phenotypes and adaptations. Such changes have occurred during the evolution of white clover. One of the most obvious has been diploidization of the NOR regions [1]. GISH confirmed this and showed the apparently complete loss of the T. pallescens NOR regions (Figure 1c-e). Another post-polyploidization change is that all 32 centromeres of $T$. repens have large blocks of TrR350 tandem repeat DNA whereas $T$. pallescens has TrR350 on only 4 chromosome pairs [14]. Concerted evolution in the allotetraploid genome has apparently led to the spread of this satellite DNA to all centromeres. 
The strong chromosome pairing affinities in hybrid 440-1 between the ancestral species implies that these diploid species evolved from a common ancestor recently enough that chromosome pairing affinity is retained, despite substantial evolutionary changes in adaptations, phenotypes and other genomic properties. By contrast, the existence of near-perfect homologous bivalent pairing in T. repens [15] suggests that the ancestral genomic pairing affinities may have been brought under genetic control or otherwise suppressed since the formation of white clover.

The use of $T$. repens as a pollen source for 440-1 effectively provided a 'genetic sieve' for unreduced female gametes from the interspecific hybrid. More than half $(26 / 44)$ of the verified, fully functional, female gametes sampled here from hybrid 440-1 were unreduced. The open pollination set-up enabled tens of thousands of hybrid florets with hundreds of thousands of egg cells to be fertilized with a mixture of $\mathrm{n}$ and $2 \mathrm{n}$ pollen. The finding of as few as 26 functional unreduced female gametes among hundreds of thousands indicated that the frequency of such gametes was very low. This also provided an insight as to why no spontaneous allotetraploids were found from either controlled crosses or open-pollination.

Transgressive gene interactions provide phenotypic innovations during hybrid speciation [31-33]. The transgressive adaptation of white clover probably arose from multiple genetic and epigenetic interactions involving complementarities and epistatic interactions between the alpine adaptation of one parent and the coastal adaptation of the other parent. An example may be the combining of the stoloniferous habit of $T$. occidentale with the ability of T. pallescens to grow in relatively infertile non-saline inland soils. This would have been accompanied by the ecological opportunity for a stoloniferous clonal herb to colonize post-glacial grasslands grazed by expanding populations of animals. Allopolyploidy would have served to stabilize the transgressive genetic and epigenetic interactions, achieve reproductive isolation, enhance fertility and probably also would have provided enhanced vegetative vigor. The raw diploid and artificial tetraploid hybrids obtained here will enable breeders to introgress traits from modern $T$. pallescens and $T$. occidentale into white clover. They may also provide a valuable resource for the study of transgressive genetic and epigenetic interactions in adaptive radiation and speciation.

\section{Implications for clover breeding}

Based on the above evidence, it is apparent that the subgenomes in white clover (designated $\mathrm{P}^{\mathrm{r}} \mathrm{P}^{\mathrm{r}} \mathrm{O}^{\mathrm{r}} \mathrm{O}^{\mathrm{r}}$ ) differ from those in contemporary T. pallescens $\left(\mathrm{P}^{\mathrm{P}} \mathrm{P}^{\mathrm{P}}\right)$ and $T$. occidentale $\left(\mathrm{O}^{\circ} \mathrm{O}^{\circ}\right)$. There is evidence for multivalent chromosome configurations in synthetic hybrids (Table 2). Hybrids between synthetic and natural forms of white clover should be $\mathrm{P}^{\mathrm{p}} \mathrm{P}^{\mathrm{r}} \mathrm{O}^{\circ} \mathrm{O}^{\mathrm{r}}$, and chromosome pairing would enable introgression of new alleles from the ancestral species into white clover. Such introgression could provide genes for new traits (e.g. drought tolerance from $T$. occidentale) as well as in-built heterotic interactions arising from new inter-sub-genomic heterozygosity. Additionally, other genomic reconfigurations such as those described for tomato interspecific introgression lines [33] and synthetic Brassica napus [34,35] may provide beneficial transgressive genomic interactions. Synthetic forms of white clover could therefore be used in breeding to improve vigor and broaden the adaptation of new cultivars, e.g. to semi-arid and saline environments.

\section{Conclusions}

Experimental evidence obtained from DNA sequence analyses, molecular cytogenetics, interspecific hybridization and breeding research is consistent with the hypothesis that the diploid alpine species T. pallescens hybridized with the diploid coastal species T. occidentale to form tetraploid T. repens. The coming together of these two species with very narrow but different adaptations, along with allotetraploidy, has produced a transgressive hybrid with a broad adaptive range. $F_{1}$ interspecific hybrids generated by embryo rescue are inter-fertile with white clover and function as synthetic white clovers, a valuable new resource for the re-incorporation of ancestral genomes into modern white clover for future plant breeding.

\section{Methods}

\section{Plant material}

Living plants used in this study were derived from seeds from the Margot Forde Forage Germplasm Centre, AgResearch Grassland Research Centre, Palmerston North, New Zealand. T. pallescens AZ1895 was of undesignated origin, while AZ4837 was collected from above Nuria, at 2,100 $\mathrm{m}$ altitude in the Spanish Pyrenees and AZ4856 was from a similar altitude in the Rotmoos Valley, Tyrol Alps, Austria. T. pallescens plants from N Greece were analyzed from herbarium samples 16156, 19230, registered for the Flora Hellenica Database. T. occidentale accessions OCD 1162 (Faro de Cabo Villano), OCD 1163 (Camarinas), OCD 1166 (Beo Peninsular) and OCD 1168 (Punta Frouxeira beach) were from sea level on the coast of NW Spain.

\section{Wide hybridization and embryo rescue}

All T. pallescens plants were self-fertile and so emasculation and hand-pollination were required. Emasculated florets were pollinated several times over two days and embryos were removed after nine days and placed on a shoot proliferating medium CR7 [36]. Developing shoots were subsequently transferred to a root initiation medium CR5 [36] before finally being planted into potting mix in the greenhouse. Putative hybrids were grown to maturity 
and verified by DNA sequence analysis of ITS and chloroplast trnL regions using methods described in [8]. At flowering, self-pollination and cross-pollination with sibs and parent species were carried out by hand in an insect-free greenhouse. Subsequently, the plants were placed outside for a full seasonal cycle to open-pollinate with the parental species and white clover. Seed-set under these conditions provided an indication of female fertility. Male fertility was estimated by extracting mature pollen onto a microscope slide, staining with $2 \%$ acetocarmine, and counting the number of full-sized, fully stained grains in a minimum sample of 300 grains (200x magnification). The white clover plants used in this study carried the co-dominant leaf markings 'white V' and/or 'red leaf', conditioned by alleles at the $\mathrm{V}$ and $\mathrm{R}$ loci, respectively [15]. Expression of these alleles in progeny derived from using these plants as male parents provided evidence of paternity. DNA sequence analysis of the chloroplast trn $\mathrm{L}$ regions of the progeny were used to verify maternity.

\section{Chromosome doubling and subsequent crossing with white clover}

Colchicine-doubling of 440-1 axillary meristems was carried out by a previously described method [37] using $0.07 \%$ colchicine for 60 hours in the dark at $4{ }^{\circ} \mathrm{C}$. Chromosome doubled plants were identified initially by increased pollen stainability and verified by morphology of dry pollen grains and chromosome counts. All progeny were verified using leaf marks and/or ITS and chloroplast DNA sequences.

\section{DNA analysis and molecular cytogenetics}

Somatic chromosome preparations were obtained from actively growing root tips after hydrolyzing with $\mathrm{HCl}$ and squashing in acetocarmine or using a flame-drying technique after enzymatic maceration as described earlier [1]. Meiotic chromosome preparations were obtained by squashing pollen mother cells from young floral buds either after enzymatic maceration or after staining with alcoholic hydrochloric acid carmine [38]. Somatic and meiotic preparations obtained after enzymatic maceration were used for GISH-FISH experiments.

Total DNA was prepared from fresh leaf samples using the method of Lefort and Douglas [39] with modifications as described in [8]. Total DNA was prepared from herbarium-derived leaf samples using the DNeasy Plant Mini Kit (QIAGEN, Germany) using the manufacturer's protocol, except that the elution buffer was pre-heated to $65{ }^{\circ} \mathrm{C}$. The nuclear ITS and chloroplast truL intron regions were amplified and sequenced as described in [8]. The DNA probes for GISH-FISH experiments were: genomic DNA of T. occidentale and T. pallescens; $\mathrm{p} T \mathrm{Tr} 5$ (GenBank AF072692), a 596 bp fragment from T. repens representing part of the $5 \mathrm{~S}$ rDNA gene family; and pTr18S (GenBank AF071069), a 1.8 kb fragment from
T. repens containing almost an entire $18 \mathrm{~S}$ rDNA sequence. Genomic DNA, isolated from T. pallescens and $T$. occidentale, and the two types of rDNA were individually labeled with fluorochrome-labeled nucleotides Cy3-dCTP or FluorX-dCTP (GE Healthcare) by nick translation according to the manufacturer's specifications. Procedures for in situ hybridization, post-hybridization stringent washing and DAPI counterstaining of chromosomes have been described [1,30]. Somatic chromosomes from $T$. repens and somatic as well as meiotic chromosomes from hybrid 440-1 were subjected to GISH-FISH using Fluor-X-labeled genomic DNA of T. pallescens and Cy3-labeled $18 \mathrm{~S}$ rDNA. After recording the images, the same somatic preparations from $T$. repens and hybrid 440-1 were re-probed for reciprocal GISH-FISH using Cy3-labeled genomic DNA of T. occidentale and FluorX-labeled $5 \mathrm{~S}$ rDNA. The former GISH-FISH experiment included unlabeled T. occidentale genomic DNA while the latter experiment included T. pallescens genomic DNA as blocking DNAs. Slides were examined under a Nikon Microphot-SA epifluorscence microscope. The images were captured using an AxioCam MRm CCD camera (Carl Zeiss GmbH, Germany) attached to the microscope and processed with ISIS imaging software (MetaSystems $\mathrm{GmbH}$, Germany). Individual photographs were composed on plates using Adobe Photoshop software.

\section{Acknowledgements}

We thank Dr Tony Conner for editing the manuscript, Michelle Williamson and Helen van den Ende for technical assistance, Prof Arne Strid for herbarium leaf samples and botanical habitat information and Dr Josef Stuefer, Dr Adriana Ravagnani and Prof C Raffl for seeds of T. pallescens. The project was funded by the New Zealand Foundation for Research, Science \& Technology (C10X0711) and AgResearch (A11406).

\section{Authors' contributions}

All authors were involved in designing and planning the research. NWE carried out DNA work, analyzed DNA sequences and supported molecular cytogenetics, HAA performed and analyzed molecular cytogenetics experiments, IMV made the hybrids, carried out embryo rescue and generated derived progeny, SWH provided cytological results, WMW derived and analyzed progeny and wrote the paper. All authors read and approved the final manuscript.

Received: 30 January 2012 Accepted: 24 April 2012 Published: 24 April 2012

\section{References}

1. Ansari HA, Ellison NW, Reader SM, Badaeva ED, Frieb B, Miller TE, Williams WM: Molecular cytogenetic organisation of $5 S$ and 18S-26S rDNA loci in white clover (Trifolium repens L.) and related species. Ann Bot 1999, 83:199-206

2. Badr A, Sayed-Ahmed H, El-Shanshouri A, Watson L: Ancestors of white clover (Trifolium repens L.) as revealed by isozyme polymorphisms. Theor Appl Genet 2002, 106:143-148.

3. Brewbaker JL, Keim WF: A fertile interspecific hybrid in Trifolium. Am Nat 1953, 87:323-326.

4. Williams WM: Taxonomy and biosystematics of Trifolium repens. In White clover. Edited by Baker MJ, Williams WM. UK: CABI; 1987:323-342.

5. Chen CC, Gibson PB: Barriers to hybridization of Trifolium repens with related species. Can J Genet Cytol 1972, 14:591-595.

6. Gibson PB, Beinhart G: Hybridization of Trifolium occidentale with two other species of clover. J Hered 1969, 60:93-96. 
7. Williams WM, Ansari HA, Hussain SW, Ellison NW, Williamson ML, Verry IM: Hybridisation and introgression between two diploid wild relatives of white clover, Trifolium nigrescens Viv. and T. occidentale Coombe. Crop Sci 2008, 48:139-148.

8. Ellison NW, Liston A, Steiner JJ, Williams WM, Taylor NL: Molecular phylogenetics of the clover genus (Trifolium - Leguminosae). Mol Phylogenet Evol 2006, 39:688-705.

9. Coombe DE: Trifolium occidentale, a new species related to T. repens $\mathrm{L}$. Watsonia 1961, 5:68-87.

10. Raffl C, Holderegger R, Parson W, Erschbamer B: Patterns in genetic diversity of Trifolium pallescens populations do not reflect chronosequence on alpine glacier forelands. Heredity 2008, 100:526-532.

11. Hand ML, Ponting RC, Drayton MC, Lawless KA, Cogan NOI, Brummer EC, Sawbridge TI, Spangenberg GC, Smith KF, Forster JW: Identification of homologous, homoeologous and paralogous sequence variants in an outbreeding allopolyploid species based on comparison with progenitor taxa. Mol Genet Genomics 2008, 280:293-304.

12. Williams WM, Griffiths AG, Hay MJM, Richardson KA, Ellison NW, Rasmussen S, Verry IM, Collette V, Hussain SW, Thomas RG, Jones CS, Anderson C, Maher D, Scott AG, Hancock A, Williamson ML, Tilbrook JC, Greig M, Allan A: Development of Trifolium occidentale as a plant model system for perennial clover species. In Molecular breeding of forage and turf. Proceedings of the 5th International Symposium on the Molecular Breeding of Forage \& Turf, 1-7 July 2007, Sapporo, Japan. Edited by Yamada T, Spangenberg G. New York: Springer; 2009:45-53.

13. Lysak MA, Lexer C: Towards the era of comparative evolutionary genomics in Brassicaceae. Plant Syst Evol 2006, 259:175-198.

14. Ansari HA, Ellison NW, Griffiths AG, Williams WM: A lineage-specific centromeric satellite sequence in the genus Trifolium. Chromosome Res 2004, 12:1-11.

15. Williams WM: Genetics and breeding. In White clover. Edited by Baker MJ, Williams WM. UK: CABI; 1987:343-419.

16. Leitch AR, Leitch IJ: Genomic plasticity and the diversity of polyploid plants. Science 2008, 320:481-483.

17. Taberlet P, Fumagalli L, Wust-Saucy A-G, Cossons J-F: Comparative phylogeography and postglacial colonization routes in Europe. Mol Ecol 1998, 7:453-464

18. Hewitt G: The genetic legacy of the Quaternary ice ages. Nature 2000, 405:907-913.

19. Zohary M, Heller D: The genus Trifolium. Jerusalem: Israel Academy of Sciences and Humanities; 1984.

20. Walker MJC: Climatic changes in Europe during the last glacial/ interglacial transition. Quat Internat 1995, 28:63-76.

21. Corriveau JL, Coleman AW: Rapid screening method to detect potential biparental inheritance of plastid DNA and results for over 200 angiosperm species. Amer J Bot 1988, 75:1443-1458.

22. Williams WM, Verry IM, Ansari HA, Hussain SW, Ullah I, Williamson ML, Ellison NW: Eco-geographically divergent diploids, Caucasian clover (Trifolium ambiguum) and western clover ( $T$. occidentale) retain most requirements for hybridisation. Ann Bot 2011, 108:1269-1277.

23. Williams WM, Nichols SN: Trifolium. In Wild crop relatives: genomic and breeding resources, legume crops and forages. Edited by Kole C. Heidelberg, Berlin: Springer; 2011:249-272.

24. Williams WM, Verry IM, Ellison NE: A phylogenetic approach to germplasm use in clover breeding. In Breeding for success: diversity in action, Proceedings of the $13^{\text {th }}$ Australasian Plant Breeding Conference, Christchurch, New Zealand, 18-21 April 2006. Edited by Mercer CF. Christchurch: New Zealand Grassland Association; 2006:966-971.

25. Corkill L: Cyanogenesis in white clover (Trifolium repens L.). I. Cyanogenesis in single plant. NZ J Sci Technol Sect B 1940, 22:65-67.

26. Kakes $\mathrm{P}$, Chardonnens A-N: Cyanotypic frequencies in adjacent and mixed populations of Trifolium occidentale Coombe and Trifolium repens L. are regulated by different mechanisms. Biochem Syst Ecol 2000, 28:633-649.

27. Williams WM, Williamson ML: Genetic polymorphism for cyanogenesis and linkage at the linamarase locus in Trifolium nigrescens Viv. subsp. nigrescens. Theor Appl Genet 2001, 103:1211-1215.

28. Olsen KM, Sutherland BL, Small LL: Molecular evolution of the Li/li chemical defence polymorphism in white clover (Trifolium repens L.). Mol Ecol 2007, 16:4180-4193.

29. Brewbaker $\mathrm{J}$ : Studies of oppositional allelism in Trifolium nigrescens. Hereditas 1955, 41:367-375.
30. Ansari HA, Ellison NW, Williams WM: Molecular and cytogenetic evidence for an allotetraploid origin of Trifolium dubium (Leguminosae). Chromosoma 2008, 117:159-167.

31. Riesberg LH, Archer MA, Wayne RK: Transgressive segregation, adaptation and speciation. Heredity 1999, 83:363-372.

32. Bell MA, Travis MP: Hybridization, transgressive segregation, genetic covariation, and adaptive radiation. Trends Ecol Evol 2005, 20:358-361.

33. Shivaprasad PV, Dunn RM, Santos BACM, Bassett A, Baulcombe DC: Extraordinary transgressive phenotypes of hybrid tomato are influenced by epigenetics and small silencing RNAs. EMBO J 2012, 31:257-266.

34. Gaeta RT, Pires JC, Iniguez-Luy F, Leon E, Osborn TC: Genomic changes in resynthesized Brassica napus and their effect on gene expression and phenotype. Plant Cell 2007, 19:3403-3417.

35. Zou J, Zhu J, Huang S, Tian E, Xiao Y, Fu D, Tu J, Fu T, Meng J: Broadening the avenue of intersubgenomic heterosis in oilseed Brassica. Theor Appl Genet 2010, 120:283-290.

36. White DWR, Voisey C: Prolific direct regeneration from cotyledons of white clover. Plant Cell Rep 1994, 13:303-308.

37. Hussain SW, Williams WM, Mercer CF, White DWR: Transfer of clover cyst nematode resistance from Trifolium nigrescens Viv. to $T$. repens $L$ by interspecific hybridisation. Theor Appl Genet 1997, 95:1274-1281.

38. Snow R: Alcoholic hydrochloric acid-carmine as a stain for chromosomes in squash preparations. Stain Technol 1963, 38:9-13.

39. Lefort F, Douglas GC: An efficient micro-method of DNA isolation from mature leaves of four hardwood tree species Acer, Fraxinus, Prunus and Quercus. Ann For Sci 1999, 56:259-263.

doi:10.1186/1471-2229-12-55

Cite this article as: Williams et al:: Experimental evidence for the ancestry of allotetraploid Trifolium repens and creation of synthetic forms with value for plant breeding. BMC Plant Biology 2012 12:55.

\section{Submit your next manuscript to BioMed Central and take full advantage of:}

- Convenient online submission

- Thorough peer review

- No space constraints or color figure charges

- Immediate publication on acceptance

- Inclusion in PubMed, CAS, Scopus and Google Scholar

- Research which is freely available for redistribution 